\section{Corneal Intelligence}

\section{Ian Murdoch}

Institute of Ophthalmology, Bath Street, London

In 2002, the ocular hypertension treatment study (OHTS) published their results. ${ }^{1,2}$ This study had taken 1636 ocular hypertensives (IOP $24-32 \mathrm{mmHg}$ ) and randomized them to receive therapy or no therapy. The primary outcome of the study was conversion to glaucoma and a secondary outcome was investigating risk factors for conversion to glaucoma. Ocular hypertensive subjects who received topical glaucoma medication experienced conversion to glaucoma at half the rate of subjects who were monitored without treatment. Risk factors for converting to glaucoma included older age, higher intraocular pressure, larger cup-disc ratio, higher pattern $\mathrm{SD}$, and thinner central corneal thickness.

Figure 1 is the famous illustration from the OHTS paper graphically demonstrating the findings concerning corneal thickness. There followed a massive flurry of interest in central corneal thickness, what does it all mean?

Intraocular pressure is the level at which the pressure inside the coats of the eye exceeds atmospheric pressure. It is expressed in

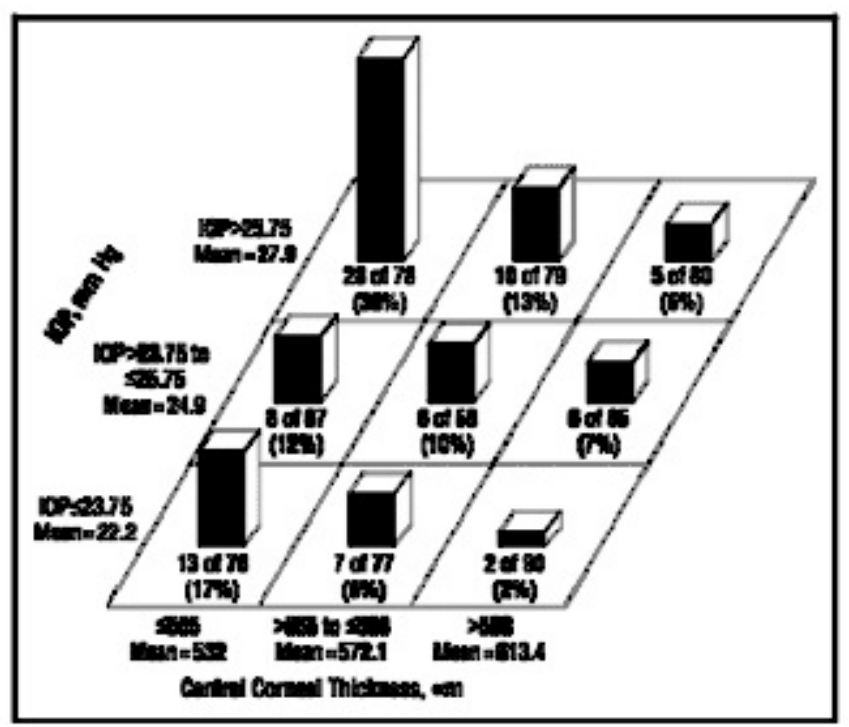

Figure 1. The percentage of participants in the observation group who developed primary open-angle glaucoma (median follow-up, 72 months) grouped by baseline intraocular pressure (IOP) of $\leq 23.75 \mathrm{mmHg}$, $>23.75 \mathrm{mmHg}$ to $\leq 25.75 \mathrm{mmHg}$, and $>25.75 \mathrm{mmHg}$ and by central corneal thickness measurements of $\leq 555 \mu \mathrm{m}$ to $>555 \mu \mathrm{m}$ to $\leq 588 \mu \mathrm{m}$, and $>588 \mu \mathrm{m}$. These percentages are not adjusted for length of follow-up. The means are not identical to those given in the text, which include all participants in the Ocular Hypertension Treatment Study rather than just the observation group. millimetres of mercury and is estimated by various techniques. The current 'gold standard' is Goldmann applanation tonometry. In this, it was calculated that for a normal eye, the natural 'spring' of the 'squashed' cornea is cancelled out by the meniscus force the other way. When the mires are adjusted and $3.06 \mathrm{~mm}^{2}$ compressed, the tonometer force approximates to the intraocular pressure (figure 2). Clearly the 'stiffness' of the cornea will change this, if less 'stiff' then the tonometer will underread and if more 'stiff' it will overread. Dynamic contour tonometry is one method proposed to overcome this source of error.

The combination of these two points has lead to the estimation of corneal thickness being part of the routine assessment for

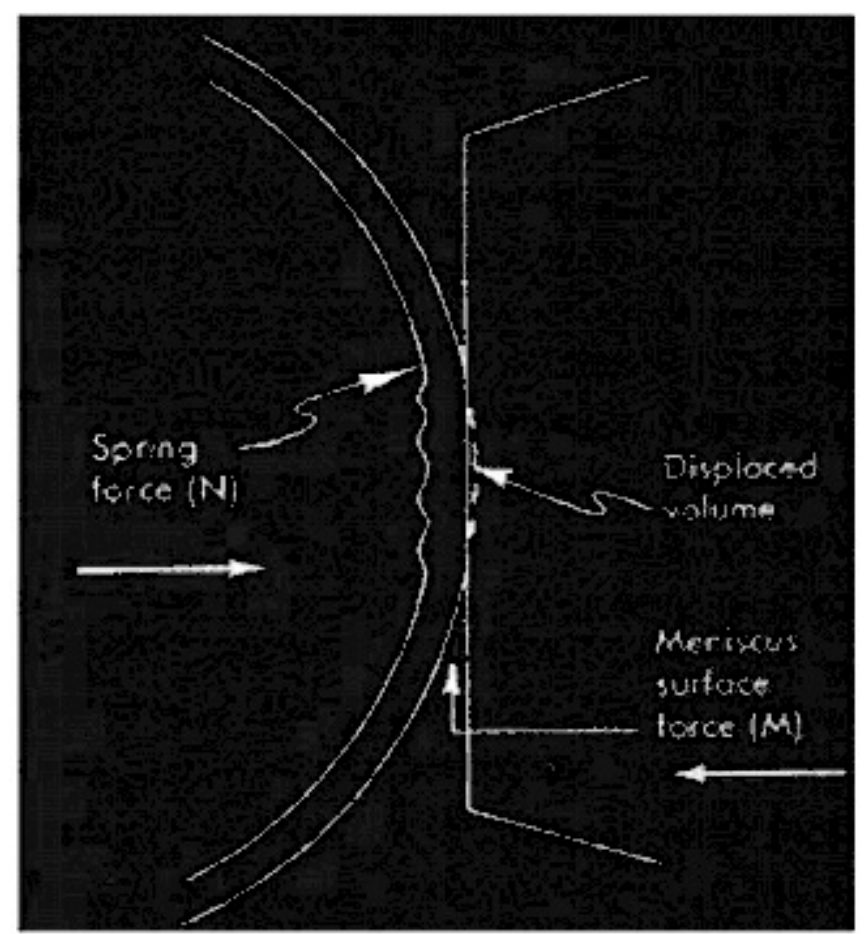

Figure 2. Spring force (stiffness) of the indented cornea $(\mathrm{N})$ is cancelled out by meniscus forces pulling the tonometer head inwards (M) at a compression of $3.06 \mathrm{~mm}^{2}$

glaucoma. I would like to make a few personal points of view on the issue.

1. Since OHTS raised the topic, research has moved towards corneal hysteresis (the damping effect of the tissue to an applied force) or corneal compliance being the major risk factor 
for glaucoma. ${ }^{3}$ Whilst corneal hysteresis is correlated with central corneal thickness, the relationship is not strong. ${ }^{4}$

2. Refractive surgery will affect the IOP assessment and we need to be aware of this.

3. 'Stiffness' of the cornea is in part due to thickness of the cornea but another vital contributor is tissue elasticity. Thus all estimates of 'true pressure' using simply corneal thickness to 'correct' an applantion tonometry reading are open to large error margins until a good assessment of corneal stiffness is available or methods of applanation that are independent of this contribution to the pressure measurement are adopted.

4. Whilst the 'true pressure' of an eye helps differentiate ocular hypertension patients and risk I would argue that it matters little in treatment. The diagnosis of glaucoma is made on disc appearance together with matching field change. The management of glaucoma remains, for the most part, to lower intraocular pressure. For each patient this is a relative, not absolute, thing. In other words, if the pressure measurement starts at $24 \mathrm{mmHg}$ then we aim lower, similarly if it starts at $12 \mathrm{mmHg}$ we aim lower. The pressure assessment is made in the same eye with the same corneal stiffness and hysteresis each time, hence is relative.

5. Like all measurements, especially physiological, corneal thickness has error margins, hence more than one measurement should be taken for more accurate categorization of patients. ${ }^{5}$ In addition, the measurement gradually decreases with time (about 0.6 um per year). ${ }^{6}$

\section{REFERENCES}

1. Kass MA, Heuer DK, Higginbotham EJ, Johnson CA, Keltner JL, Miller JP et al. The Ocular Hypertension Treatment Study: a randomized trial determines that topical ocular hypotensive medication delays or prevents the onset of primary open-angle glaucoma. Arch Ophthalmol 2002; 120(6): 701-13.

2. Gordon MO, Beiser JA, Brandt JD, Heuer DK, Higginbotham EJ, Johnson CA et al. The Ocular Hypertension Treatment Study: baseline factors that predict the onset of primary open-angle glaucoma. Arch Ophthalmol 2002; 120(6): 714-20.

3. Wells AP, Garway-Heath DF, Poostchi A, Wong T, Chan KC, Sachdev N. Corneal hysteresis but not corneal thickness correlates with optic nerve surface compliance in glaucoma patients. Invest Ophthalmol Vis Sci 2008; 49(8): 3262-8.

4. Kotecha A, Elsheikh A, Roberts CR, Zhu H, Garway-Heath DF. Corneal thickness- and age-related biomechanical properties of the cornea measured with the ocular response analyzer. Invest Ophthalmol Vis Sci 2006; 47(12): 5337-47.

5. Wickham L, Edmunds B, Murdoch IE. Central corneal thickness: will one measurement suffice? Ophthalmology 2005;112(2): 225-8.

6. Brandt JD, Gordon MO, Beiser JA, Lin SC, Alexander MY, Kass MA. Changes in central corneal thickness over time: the ocular hypertension treatment study. Ophthalmology 2008; 115(9): 1550-1556. 